\title{
Comparison of HPV testing by real-time fluorescent PCR and he2 for detection of high-grade cervical intraepithelial neoplasia and cancer: a case- control study in high-risk patients.
}

\author{
Xinxin Du, Shufang Jiang, Aijun Liu, Yurong Fu, Yun Zhang, Yuanguang Meng* \\ Department of Obstetrics and Gynecology, Chinese PLA General Hospital, 28 Fuxing Road, Beijing, PR China
}

\begin{abstract}
Introduction: HPV testing is more sensitive than cytology for cervical cancer screening but leads to over referral to colposcopy. This study was designed to evaluate the correlation of development of high-grade cervical intraepithelial neoplasia and cancer with HPV infection tested by real-time fluorescent polymerase chain reaction and conventional hc2 respectively and to find a cut-off value of HPV tests to increase the specificity of HPV testing and facilitate the triage before colposcopy.

Material and methods: Retrospective analysis the clinical data of 21,550 outpatients receiving cervical cancer screening, real-time PCR and hc2 testing were randomly chosen to test samples. Colposcopy with biopsies was performed to high-risk patients. Histopathology was taken as the diagnostic gold standard. Univariate ANOVA and multivariate binary logistic regression were adopted for data analysis.

Results: The sensitivity and positive predictive value was $98.9 \%$ and $40.4 \%$ of hc2, $93.8 \%$ and $42.6 \%$ of RT-PCR respectively. Spearman rank correlation coefficient of viral load and lesions is $0.246, P=0.000$. Comparing with HPV negative cases, the risk of having HSIL and cervical cancer for 16/18 genotypes positive cases was 11.7 fold-higher $(\mathrm{OR}=11.71,95 \%$ CI: 3.75-36.61). The risk for other 11 genotypes positive cases was 3.1 fold-higher $(\mathrm{OR}=3.10,95 \% \mathrm{CI}$ : $\mathbf{0 . 9 7 - 9 . 8 5})$. The risk for high-level of viral load group $\left(1 \times 10^{5} \sim 10^{7}\right)$ was significantly higher than the negative group (OR=1.98, 95\% CI: 1.43-2.74).

Conclusion: Real-time fluorescent polymerase chain reaction HPV detection method has better specificity and positive predictive value than conventional hc2. There is no optimal cut-off value of HPV viral load by he2 to predict the development of cervical lesions. Patients with positive HPV 16/18 and high-level viral load by RT-PCR test have more risk to develop high-grade cervical lesions and carcinoma. Screening specificity is increased when taking these two cut-offs as the criteria to triage before colposcopy.
\end{abstract}

Keywords: Human papilloma virus, Cervical cancer, RT-PCR, Triage.

Accepted on October 26, 2017

\section{Introduction}

A number of clinical trials have proved that HPV DNA testing is more sensitive but less specific than cytology, with greater reproducibility [1] and better negative predictive value against cervical precancer and cancer [1,2]. In the year 2012, American Cancer Society-American Society for Colposcopy and Cervical Pathology-American Society for Clinical Pathology (ACS-ASCCP-ASCP) introduced HPV testing in the cervical cancer screening guideline as cotesting strategy for women 30-65 y of age with a 5 y interval [3]. U.S. Preventive Services Task Force (USPSTF) made the same recommendation in the latest released statement [4] after the publication of POBASCAM randomised controlled trial [5]. Hybrid Capture 2 (hc2) is approved in the USA by the Food and Drug Administration (FDA) for primary screening. Other candidate HPV testing technologies should have a clinical sensitivity not less than $90 \%$ and specificity not less than $98 \%$ of the hc2 for cervical intraepithelial neoplasia grade 2 or 3 and treatable cancer ( $\geq$ CIN 2) in women of at least 30 y [6]. Subsequently, in 2015, ASCCP and the Society of Gynecologic Oncology (SGO) published interim guidance for the use of HPV testing for cervical cancer primary screening [7]. In 2016, it was considered as an alternative modality to cotesting for women 25 years and older in practice bulletin from the American College of Obstetricians and Gynecology (ACOG) [8]. Advanced HPV diagnosis provides important estimates of the prevalence of cytologic abnormalities, hrHPV positivity, and CIN2 or greater [9].

Multiple researches have proved that HPV testing is of optimal sensitivity, reproducibility and predictive value in primary screening [9-14]. However, it elevates the chance of over referral to colposcopy as overtreatment, which is considered as the primary measure of harm outcome of screening. This study was designed to evaluate the correlation of high-grade cervical intraepithelial neoplasia and cancer with HPV infection tested 
by real-time fluorescent polymerase chain reaction and conventional hc2 respectively and to find a cut-off value of HPV tests to increase the specificity of HPV testing and facilitate the triage before colposcopy.

\section{Methods}

\section{Study design}

Data collection was performed from September 2014 to February 2016. All 21,550 consecutive patients received cervical cancer screening test by cytology and HPV contesting modality, 1,099 patients had abnormal screening results and was defined high-risk cervical cancer patients, undergoing biopsy under colposcopy.

\section{HPV testing}

Cervical swabs samples were subject to DNA extraction and real-time PCR system based on the fluorogenic 5'nuclease assay and Taqmantechnique (from Liferiver ${ }^{\mathrm{TM}}$, China) that detects HPV 16, 18, 31, 33, 35, 39, 45, 51, 52, 56, 58, 59, 66 and 68 genotypes separately.

\section{Pathology}

Histopathology was taken as the diagnostic gold standard. We use 2-tiered terminology, i.e. Low Grade Squamous Intraepithelial Lesion (LSIL) and High Grade Squamous Intraepithelial Lesion (HSIL) instead of 3-tiered CIN system. CIN2 with P16 positive equals to HSIL, presupposing to have increased cancer risk. CIN2 with P16 negative equals to LSIL [15]. In this study, HSIL and cervical cancer were defined as pathology positive. LSIL and normal pathological result were defined as pathology negative.

\section{Data analysis}

Univariate ANOVA and multivariate binary logistic regression analysis were used to analyse the correlation of cervical abnormalities with HPV infection by SPSS version 23.0. Values of $\mathrm{p}<0.05$ were considered statistically significant.

\section{Ethical approval}

This study was approved by the Ethical Committee of People's Liberation Army General Hospital. Written informed consent was obtained from each patient.

\section{Results}

\section{HPV positive rate and prevalence of cervical lesions}

There were 623 samples tested by hc 2 technique and 969 cases by RT-PCR technique, 493 samples were tested by both realtime fluorescent PCR and hc2. HPV positive rate had no significant difference among the four age groups by hc2 ( $\mathrm{P}>0.05$ ) while by RT-PCT testing $\mathrm{P}<0.05$ (Table 1 ).
Among 1,099 cases, 496 (45.1\%) cases were with normal pathologic result, $232(21.1 \%)$ were LSIL, 327 (29.8\%) were HSIL and $44(4.0 \%)$ were cervical cancer. Forty-tow cases were squamous cell carcinoma and 2 cases were adenocarcinoma. By hc2 testing, the incidence rate of HSIL and cervical cancer was not statistically different among four groups $\left(\chi^{2}=6.618, \mathrm{P}=0.085\right)$. By RT-PCR testing, there was significant difference $\left(\chi^{2}=15.620, \mathrm{P}=0.001\right)$. The sensitivity and Positive Predictive Value (PPV) of Hc2 in 493 cases is $98.9 \%$ and $40.4 \%$, respectively. That of RT-PCR is $93.8 \%$ and $42.6 \%$, respectively. The sensitivity of RT-PCR is $94.8 \%$ of hc 2 and specificity is $163.4 \%$ of hc 2 , respectively.

\section{Correlation analysis of HPV infection by he2 and cervical lesions}

The viral load $(\mathrm{X} \pm \mathrm{SD})$ in normal result, LSIL, HSIL and cancer groups was $518.64 \pm 823.50 \mathrm{pg} / \mathrm{ml}, 887.83 \pm 951.78$ $\mathrm{pg} / \mathrm{ml}, \quad 577.41 \pm 706.89 \mathrm{pg} / \mathrm{ml}, 499.10 \pm 627.49 \mathrm{pg} / \mathrm{ml}$, respectively. It has significant differences among 4 groups $(\mathrm{P}=0.001)$, while was not statistically significant among the three abnormal groups $(\mathrm{P}=0.669)$. Spearman rank correlation coefficient of viral load and lesions is $0.246, \mathrm{P}=0.000$.

\section{HPV testing by RT-PCR}

Infection of the 13 carcinogenic hrHPV: HPV16 was most commonly seen in $272(28.1 \%)$ cases. Subsequently were type 58 in $195(20.1 \%)$ cases, type 52 in $182(18.8 \%)$ cases. Type 45 was the least positive in $55(5.7 \%)$ cases. Genotype distribution in 339 HSIL and cancer cases was 16, 58, 52, and 35 was the least in cases number of 187 (55.2\%), 107 (31.6\%), $103(30.4 \%)$ and 41 (12.9\%), respectively (Figure 1).

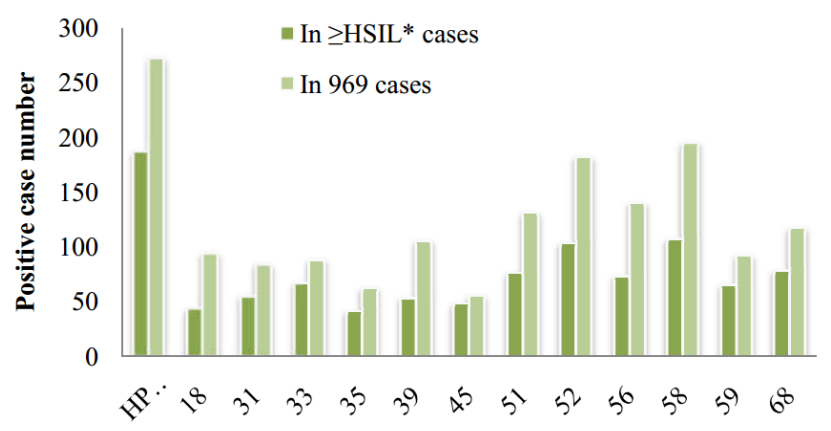

Figure 1. Data of HPV genotype prevalence. ${ }^{*} H S I L$ and cervical cancer.

\section{Correlation analysis of HPV genotypes and cervical lesions}

Patients were divided into three groups in accordance with the carried genotypes. group 1: negative; group 2: 16/18 (-), other 11 genotypes $(+)$; group 3: 16/18 $(+)$, other 11 genotypes $(+) /$ (-). Exposure to HPV 16, 18 resulted in significantly more HSIL and cancer cases than without exposure $(59.5 \%$ vs. $22.6 \%, \mathrm{P}<0.05)$. The risk of having HSIL and cancer of group 3 was 3.8 fold-higher than Group $2(\mathrm{OR}=3.79$, 95\% CI: $2.80-5.13)$, and 13.4 fold-higher than group $1(\mathrm{OR}=13.38,95 \%$ 
Comparison of HPV testing by real-time fluorescent PCR and hc2 for detection of high-grade cervical intraepithelial neoplasia and cancer: a case-control study in high-risk patients

CI: 7.93-22.57). The OR of group 2 vs. group 1 was $3.53(95 \%$ CI: 2.11-5.92), shown in Figure 2A.

\section{Correlation analysis of HPV multiple infections and cervical lesions}

Single genotype carriers (577/969) were mostly seen in HPV positive cases and one sample carried at most 5 different genotypes. Taking HPV negative group (group 1) as the reference group, the risk of having HSIL and cancer when carrying more than 4 genotypes simultaneously (group 3) increased significantly to 13 fold-higher $(\mathrm{P}<0.05)$, and 6.3 fold-higher $(\mathrm{P}<0.05)$ when carrying less than 4 genotypes (group 2), shown in Figure 2A. The OR of group 3 vs. group 2 was 2.07 (95\% CI: 0.78-5.51) (Figure 2b).

\section{Correlation analysis of HPV viral load and cervical lesions}

The viral load varies from $1 \times 10^{2}$ to $1 \times 10^{7}$. Pathology positive rate increased significantly when the viral load exceeded $1 \times 10^{5}$. The HPV negative group was set as reference group (group 1). Taking $1 \times 10^{5}$ as the cut-off value, $1 \times 10^{2}-10^{4}$ was defined as low-level (group 2) and $1 \times 10^{5}-10^{7}$ as high-level (group 3). The risk of diseases in patients with high-level viral load was 2 fold-higher than with low-level group (OR=1.95, 95\% CI: 1.43-2.66). Comparing with group 1, the OR of group 2 was 4.10 (95\% CI: 2.40-7.02) and that of group 3 was 8.01 (95\% CI: 4.83-13.28), shown in Figure 2C.

The risk for patients carrying HPV 16, 18 of high-level was 2.5 fold-higher than of low-level (OR=2.47, 95\% CI: 1.59-3.95). The proportion of patients with high-level load increased with cervical lesions grade (6.9\% of normal pathology cases, $14.6 \%$ of LSIL cases, $36.8 \%$ of HSIL cases and $73.0 \%$ of cancer cases, respectively, $\mathrm{P}=0.000$ ). The rank of viral load varied significantly among the four groups of cases, $\mathrm{P}<0.05$ in LSIL vs. HSIL, LSIL vs. cancer and HSIL vs. cancer, while $\mathrm{P}>0.05$ in normal $v s$. LSIL.
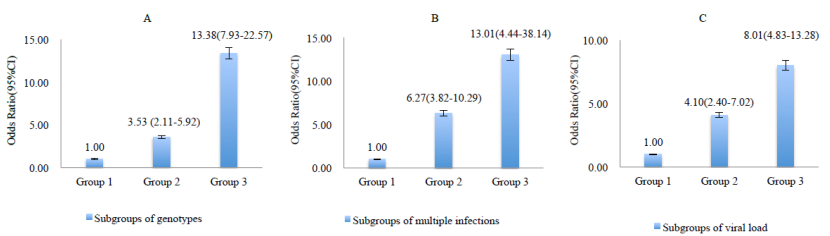

Figure 2. Univariate analysis of the risk of high-grade cervical lesions in various subgroups. A: Odds ratio of the incidence rate of HSIL and cervical cancer in the subgroups of genotypes. Group 1: No HPV infection; group 2: HPV16/18(-), other 11 genotypes (+); group 3: HPV16/18(+), other 11 genotypes $(+) /(-)$. B: Odds ratio of the incidence rate of HSIL and cervical cancer in the subgroups of multiple infections. Group 1: No HPV infection; group 2: Carrying 1 to 3 different genotypes per case; group 3: Carrying 4 to 5 different genotypes per case. C: Odds ratio of the incidence rate of HSIL and cervical cancer in the subgroups of viral load. Group 1: No HPV infection; group 2: viral load of low level $\left(1 \times 10^{2}-10^{4}\right)$; group 3: viral load of high level $\left(1 \times 10^{5}-10^{7}\right)$.

\section{Multivariate analysis}

Genotypes, multiple infections and viral load were involved in the binary logistic regression analysis (Table 2). The genotypes and viral load are two independent risk factors of the development of HSIL and cervical cancer $(\mathrm{P}<0.05)$. Number of genotypes carried by one patient had not statistical influence on high-grade cervical lesions development and was excluded from multivariate logistic analysis $(\mathrm{P}>0.05)$. There was significant positive relationship between HPV 16/18 exposure and the development of high-grade cervical lesions, with 8.5 fold increase in the risk (OR=8.48, 95\% CI: 4.82-14.92). It was 2.2 fold increase in the risk with other 11 genotypes exposure $(\mathrm{OR}=2.24,95 \%$ CI: 1.27-3.94). Regarding viral load, the OR of high-level group was 1.98 (95\% CI: 1.43-2.74).

Table 1. HPV testing by hc2 and RT-PCR techniques in several of age groups.

\begin{tabular}{|c|c|c|c|c|c|c|}
\hline \multirow[t]{2}{*}{ Age group } & \multirow[t]{2}{*}{ HPV positive number (\%) } & \multicolumn{4}{|l|}{ Pathology } & \multirow[t]{2}{*}{ Total } \\
\hline & & Normal (\%) & LSIL (\%) & HSIL (\%) & Cancer (\%) & \\
\hline \multicolumn{7}{|l|}{ hc2 } \\
\hline$<30$ & $72(93.5)$ & $37(48.1)$ & $23(29.9)$ & $17(22.1)$ & $0(0.0)$ & 77 \\
\hline $30-39$ & $197(90.8)$ & $85(39.2)$ & $56(25.8)$ & $70(32.3)$ & $6(2.8)$ & 217 \\
\hline $40-49$ & $181(86.6)$ & $87(41.6)$ & $43(20.6)$ & $66(31.6)$ & $13(6.2)$ & 209 \\
\hline$\geq 50$ & $102(85.0)$ & $61(50.8)$ & $21(17.5)$ & $29(24.2)$ & $9(7.5)$ & 120 \\
\hline Total & $552(88.6)$ & $270(43.3)$ & $143(23.0)$ & $182(29.2)$ & $28(4.5)$ & 623 \\
\hline $\mathrm{P}$ & 0.156 & 0.007 & & & & \\
\hline \multicolumn{7}{|l|}{ RT-PCR } \\
\hline$<30$ & $111(84.1)$ & $53(40.2)$ & $44(33.3)$ & $34(25.8)$ & $1(0.8)$ & 132 \\
\hline $30-39$ & $254(81.7)$ & $120(38.6)$ & $77(24.8)$ & $104(33.4)$ & $10(3.2)$ & 311 \\
\hline
\end{tabular}




\begin{tabular}{lllllll}
\hline $40-49$ & $280(81.6)$ & $135(39.4)$ & $67(19.5)$ & $126(36.7)$ & $15(4.4)$ & 343 \\
\hline$\geq 50$ & $132(72.1)$ & $110(60.1)$ & $24(13.1)$ & $38(20.8)$ & $11(6.0)$ & $37(3.8)$ \\
\hline Total & $777(80.2)$ & $418(43.1)$ & $212(21.9)$ & $302(31.2)$ & & 969 \\
\hline$P$ & 0.022 & 0 & & & & \\
\hline
\end{tabular}

Table 2. Multivariate analysis of correlation of HPV infection and high-grade cervical lesions.

\begin{tabular}{|c|c|c|c|c|}
\hline \multirow{2}{*}{$\begin{array}{l}\text { HPV } \\
\text { characteristics }\end{array}$} & \multicolumn{2}{|c|}{ Pathology, n (\%) } & \multirow[t]{2}{*}{ Adjust OR $(95 \% \mathrm{Cl})$} & \multirow[t]{2}{*}{$\mathbf{P}$} \\
\hline & Positive $^{*}$ & Negative $^{* *}$ & & \\
\hline \multicolumn{5}{|l|}{ 1. Genotype } \\
\hline Negative & $19(9.9)$ & $173(90.1)$ & 1 & 0 \\
\hline $16 / 18(-)$, others $(+)$ & $126(27.9)$ & $325(72.1)$ & $2.24(1.27-3.94)$ & \\
\hline 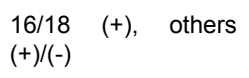 & $194(59.5)$ & $132(40.5)$ & $8.48(4.82-14.92)$ & \\
\hline \multicolumn{5}{|l|}{ 2. Multiple infections } \\
\hline 0 & $19(9.9)$ & $173(90.1)$ & 1 & 0.534 \\
\hline $1 / 3$ & $310(40.8)$ & $450(59.2)$ & & \\
\hline $4 / 5$ & $10(58.8)$ & $7(41.2)$ & $1.38(0.50-3.83)$ & \\
\hline \multicolumn{5}{|l|}{ 3. Viral load } \\
\hline 0 & $19(9.9)$ & $173(90.1)$ & 1 & 0 \\
\hline $1 \times 10^{2}-10^{4}$ & $86(31.0)$ & $19(69.0)$ & & \\
\hline $1 \times 10^{5}-10^{7}$ & $234(46.8)$ & $266(53.2)$ & $1.98(1.43-2.74)$ & \\
\hline
\end{tabular}

*High-grade squamous intraepithelial lesion and cervical cancer, ${ }^{* *}$ Normal pathology and low-grade squamous intraepithelial lesion and cervical cancer.

\section{Discussion}

HPV prevalence in cervical cancer is $99.7 \%$ worldwide [16]. HPV genotyping and viral load measurement are critical to cervical lesions detection and follow-up visit. Approximately 15 genotypes of HPV, including the 13 subtypes tested in this study, have varying carcinogenic risk and HPV tests are required to be analytically and clinically validated with proven acceptable reproducibility, clinical sensitivity, specificity and positive and negative predictive values for cervical cancer and verified precancer [6,17]. Inappropriate cut-off of HPV positive may lead to overtreatment, i.e. over referral of "virtually no risk" patients to biopsy under colposcopy. The high false positive rate is inevitably derived from high sensitivity of HPV tests and the carcinogenicity mechanism of the virus. It was traded off in population-based study, where the majority of participants were HPV negative. In this study, HSIL and cervical cancer were set as clinical end point in our research seeking the optimal cut-off of HPV positive to predict cervical lesions. HPV tests were validated by pathology result in high-risk patients defined by contesting and found that more than $60 \%$ of participants were histological negative and LSIL. The false positive rate was $82.5 \%$ of hc 2 and $71.4 \%$ of RTPCR, respectively.
HPV 16 is the most commonly seen oncogenic subtype and is associated with $55 \%-60 \%$ cervical cancer development, HPV18 accounts for $10 \%-15 \%$ subsequently and the other oncogenic genotypes account for $25 \%-35 \%$ of all cancer cases $[3,16,18,19]$. The 8 y absolute risk for $\mathrm{CIN}^{+}$of HPV16 was $21.8 \%$ [20]. In ATHENA trial, the 3 y cumulative incidence rate of $\mathrm{CIN}^{+}$after 3 y was $21.16 \%$ (95\% CI: 18.39-24.01) for HPV16/18 positive women and only 5.4\% (95\% CI: 4.5-6.4) in women with HPV genotypes other than 16 and 18 [7]. Among the 37 cancer cases in and 969 patients undergoing RT-PCR testing, $33(89.2 \%)$ is attributable to HPV $16 / 18$ positive. It shows a significantly higher risk in HPV16/18 positive group to develop high-grade cervical lesions and cancer than negative group by univariate and multivariate analysis, which is consistent with Schiffman et al. [21].

Regarding multiple infections, our result showed significantly high risk of high-grade disease development, which is consistent with Schmitt et al. [22]. In multivariate analysis, it has not statistical influence on cervical lesion development. Studies with large sample size are still required for further investigation.

The correlation of viral load by hc2 and cervical lesions grade was weak and lack of a dose response, which is consistent with Gravitt et al. [23] but is converse with Kang et al. [24] who concluded that the severity of cervical lesions increased with the increasing viral load. Through RT-PCR testing of HPV, high-level of viral load is the other independent risk factor of high-grade cervical lesions and cancer. We take $1 \times 10^{5}$ as the cut-off value to divide the viral load into high and low level. Patients with high-level of viral load have more risk to develop high-grade cervical lesions and cancer by univariate and multivariate analysis. The trend was also observed in HPV 16/18 and in HPV 16, consistent with Wu et al. [25]. Above all, it is logically presuppose that HPV testing by RT-PCR can be applied in cervical cancer screening for triage before colposcopy through genotyping and viral load measurement. In accordance with the multivariate analysis formula, genotype has more effect on disease development than viral load.

The majority of HPV infections are cleared by the immune system within 2 y [26] and if the viral gene is integrated into the host cell and express the early oncogenic protein E6 and E7 will significantly increase the risk of cervical lesions [27]. However, it is difficult to tell when the viral gene will integrate into the host cell and to discriminate between regressive and progressive infections using the DNA testing technologies. E6/E7 mRNA testing could be useful to supply evidence of progressive infection and shows relatively high specificity. However, the sensitivity is low although the application of 
E6/E7 mRNA testing for HPV may lead to a low referral to colposcopy [28]. It cannot substitute DNA-based technologies in cervical cancer screening.

In conclusions, real-time fluorescent polymerase chain reaction HPV detection method has better specificity and positive predictive value than conventional hc2. There is no optimal cut-off value of HPV viral load by hc2 to predict the development of cervical lesions. Patients with positive HPV 16/18 and high-level viral load by RT-PCR test have more risk to develop HSIL and carcinoma. Screening specificity is increased when taking these two cut-offs as the criteria to triage before colposcopy.

\section{Conflicts of Interest}

The authors declare no conflict of interest for this article. The Liferiver ${ }^{\mathrm{TM}}$ Company has no role in writing of this study, or in making any decision to the submission.

\section{Acknowledgment}

This study was supported by a grant from the National Natural Science Foundation of China (81571411).

\section{References}

1. Schiffman M, Castle PE, Jeronimo J, Rodriguez AC, Wacholder S. Human papillomavirus and cervical cancer. Lancet (London, England) 2007; 370: 890-907.

2. Schiffman M, Glass AG, Wentzensen N, Rush BB, Castle PE, Scott DR, Buckland J, Sherman ME, Rydzak G, Kirk P. A long-term prospective study of type-specific human papillomavirus infection and risk of cervical neoplasia among 20,000 women in the Portland Kaiser Cohort Study. Cancer Epidemiol Biomark Prev Am Assoc Cancer Res Am Soc Prev Oncol 2011; 20: 1398-1409.

3. Saslow D, Solomon D, Lawson HW, Killackey M, Kulasingam SL, Cain J, Garcia FA, Moriarty AT, Waxman AG, Wilbur DC, American Cancer Society, American Society for Colposcopy and Cervical Pathology, American Society for Clinical Pathology. Screening guidelines for the prevention and early detection of cervical cancer. CA Cancer J Clinic 2012; 62: 147-172.

4. Moyer VA. Screening for cervical cancer: U.S. Preventive Services Task Force recommendation statement. Ann Int Med 2012; 156: 880-891.

5. Rijkaart DC, Berkhof J, Rozendaal L, van Kemenade FJ, Bulkmans NW. Human papillomavirus testing for the detection of high-grade cervical intraepithelial neoplasia and cancer: final results of the POBASCAM randomised controlled trial. Lancet Oncol 2012; 13: 78-88.

6. Meijer CJ, Berkhof J, Castle PE, Hesselink AT, Franco EL, Ronco G, Arbyn M, Bosch FX, Cuzick J, Dillner J. Guidelines for human papillomavirus DNA test requirements for primary cervical cancer screening in women 30 years and older. Int Cancer J Int Du Cancer 2009; 124: 516-520.
7. Huh WK, Ault KA, Chelmow D, Davey DD, Goulart RA, Garcia FA, Kinney WK, Massad LS, Mayeaux EJ, Saslow D. Use of primary high-risk human papillomavirus testing for cervical cancer screening: interim clinical guidance. Gynecol Oncol 2015; 136: 178-182.

8. Practice Bulletin No. 157: Cervical cancer screening and prevention. Obstet Gynecol 2016; 127: 1-120.

9. Wright TC, Stoler MH, Behrens CM, Apple R, Derion T, Wright TL. The ATHENA human papillomavirus study: design, methods, and baseline results. Am J Obstetr Gynecol 2012; 206: 46.

10. Rijkaart DC, Berkhof J, van Kemenade FJ, Coupe VM, Rozendaal L, Heideman DA, Verheijen RH, Bulk S, Verweij W, Snijders PJ. HPV DNA testing in populationbased cervical screening (VUSA-Screen study): results and implications. Br J Cancer 2012; 106: 975-981.

11. Kitchener HC, Gilham C, Sargent A, Bailey A, Albrow R, Roberts C, Desai M, Mather J, Turner A, Moss S. A comparison of HPV DNA testing and liquid based cytology over three rounds of primary cervical screening: extended follow up in the ARTISTIC trial. Eur J Cancer 2011; 47: 864-871.

12. Ronco G, Dillner J, Elfstrom KM, Tunesi S, Snijders PJ, Arbyn M, Kitchener H, Segnan N, Gilham C, Giorgi-Rossi P. Efficacy of HPV-based screening for prevention of invasive cervical cancer: follow-up of four European randomised controlled trials. Lancet (London, England) 2014; 383: 524-532.

13. Katki HA, Kinney WK, Fetterman B, Lorey T, Poitras NE, Cheung L, Demuth F, Schiffman M, Wacholder S, Castle PE. Cervical cancer risk for women undergoing concurrent testing for human papillomavirus and cervical cytology: a population-based study in routine clinical practice. Lancet Oncol 2011; 12: 663-672.

14. Gage JC, Schiffman M, Katki HA, Castle PE, Fetterman B, Wentzensen N, Poitras NE, Lorey T, Cheung LC, Kinney WK. Reassurance against future risk of precancer and cancer conferred by a negative human papillomavirus test. J Nat Cancer Inst 2014; 106.

15. Darragh TM, Colgan TJ, Thomas Cox J, Heller DS, Henry MR, Luff RD, McCalmont T, Nayar R, Palefsky JM, Stoler $\mathrm{MH}$. The lower anogenital squamous terminology standardization project for HPV-associated lesions: background and consensus recommendations from the College of American Pathologists and the American Society for Colposcopy and Cervical Pathology. Off J Int Soc Gynecol Patholog 2013; 32: 76-115.

16. Walboomers JM, Jacobs MV, Manos MM, Bosch FX, Kummer JA, Shah KV, Snijders PJ, Peto J, Meijer CJ, Munoz N. Human papillomavirus is a necessary cause of invasive cervical cancer worldwide. J Pathol 1999; 189: 12-19.

17. Stoler MH, Castle PE, Solomon D, Schiffman M. The expanded use of HPV testing in gynecologic practice per ASCCP-guided management requires the use of wellvalidated assays. Am J Clin Pathol 2007; 127: 335-337. 
18. de Sanjose S, Quint WG, Alemany L, Geraets DT, Klaustermeier JE, Lloveras B, Tous S, Felix A, Bravo LE, Shin HR. Human papillomavirus genotype attribution in invasive cervical cancer: a retrospective cross-sectional worldwide study. Lancet Oncol 2010; 11: 1048-1056.

19. Munoz N, Bosch FX, de Sanjose S, Herrero R, Castellsague $\mathrm{X}$, Shah KV, Snijders PJ, Meijer CJ. Epidemiologic classification of human papillomavirus types associated with cervical cancer. N Engl J Med 2003; 348: 518-527.

20. Thomsen LT, Frederiksen K, Munk C, Junge J, Iftner T. Long-term risk of cervical intraepithelial neoplasia grade 3 or worse according to high-risk human papillomavirus genotype and semi-quantitative viral load among 33,288 women with normal cervical cytology. Int J Cancer 2015; 137: 193-203.

21. Schiffman M, Boyle S, Raine-Bennett T, Katki HA, Gage JC, Wentzensen N, Kornegay JR, Apple R, Aldrich C, Erlich HA. The role of human papillomavirus genotyping in cervical cancer screening: a large-scale evaluation of the cobas HPV test. Cancer Epidemiol Biomark Prev Assoc Cancer Res Am Soc Prev Oncol 2015; 24: 1304-1310.

22. Schmitt M, Depuydt C, Benoy I, Bogers J, Antoine J, Arbyn M, Pawlita M. Multiple human papillomavirus infections with high viral loads are associated with cervical lesions but do not differentiate grades of cervical abnormalities. J Clin Microbiol 2013; 51: 1458-1464.

23. Gravitt PE, Burk RD, Lorincz A, Herrero R, Hildesheim A, Sherman ME, Bratti MC, Rodriguez AC, Helzlsouer KJ, Schiffman M. A comparison between real-time polymerase chain reaction and hybrid capture 2 for human papillomavirus DNA quantitation. Cancer Epidemiol Biomark Prev Assoc Cancer Res Am Soc Prev Oncol 2003; 12: 477-484.
24. Kang L, Zhao F, Chen F, Chen W, Li J, Zhang X, Qiao Y. Value of high risk human papillomavirus viral load in predicting cervical lesions and triaging for high risk (HR)HPV-positive women. Zhonghua Zhong Liu Za Zhi Chinese J Oncol 2014; 36: 316-320.

25. Wu Z, Qin Y, Yu L, Lin C, Wang H, Cui J, Liu B, Liao Y, Warren D, Zhang X. Association between human papillomavirus (HPV) 16, HPV18, and other HR-HPV viral load and the histological classification of cervical lesions: Results from a large-scale cross-sectional study. J Med Virol 2017; 89: 535-541.

26. Giuliano AR, Lee JH, Fulp W, Villa LL, Lazcano E, Papenfuss MR, Abrahamsen M, Salmeron J, Anic GM, Rollison DE. Incidence and clearance of genital human papillomavirus infection in men (HIM): a cohort study. Lancet (London, England) 2011; 377: 932-940.

27. Peralta-Zaragoza O, Deas J, Gomez-Ceron C, GarciaSuastegui WA, Fierros-Zarate Gdel S, Jacobo-Herrera NJ. HPV-based screening, triage, treatment, and followup strategies in the management of cervical intraepithelial neoplasia. Obstetr Gynecol Int 2013; 2013: 912780.

28. Liu TY, Xie R, Luo L, Reilly KH, He C, Lin YZ, Chen G, Zheng XW, Zhang LL, Wang HB. Diagnostic validity of human papillomavirus E6/E7 mRNA test in cervical cytological samples. J Virol Meth 2014; 196: 120-125.

\section{*Correspondence to}

Yuanguang Meng

Department of Obstetrics and Gynecology

Chinese PLA General Hospital

PR China 